\title{
El archivo musical documental: subjetividades y aportaciones al sujeto cultural
}

\author{
Ruth Nayibe Cárdenas Soler ${ }^{1}$ (D) \\ Adriana Marien Gutiérrez Torres ${ }^{2}-$ \\ Rosa María Palencia Dotor ${ }^{3}$
}

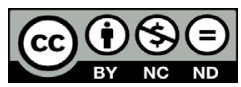

1. Universidad Pedagógica y Tecnológica de Colombia, Colombia ruth.cardenas@uptc.edu.co

2. Universidad Pedagógica y

Tecnológica de Colombia, Colombia

3. Institución Educativa Técnica

Chicamocha, Colombia

Recibido: 30/05/2021

Revisado: 05/07/2021

Aprobado: 02/09/2021

Publicado: 01/01/2022

\section{Resumen}

Este artículo surge de una investigación interesada en la recuperación del material documental - partituras musicales- usado por la Orquesta Sinfónica de Vientos de Boyacá, cuyo origen se remonta a finales del siglo XIX. La agrupación tuvo varias transiciones en cuanto a su función y a su pertenencia organizacional. En 2004 hubo una reestructuración interna que provocó el inicio de su decadencia. El estudio fue cualitativo-descriptivo, con un enfoque histórico-hermenéutico. Estuvo dividido en las siguientes fases: (1) diagnóstico, (2) clasificación, caracterización y valoración, (3) organización de la colección documental y (4) catalogación. Como resultado, se consolidó un catálogo de 328 compositores y 757 obras, organizado según criterios archivísticos y dispuesto para ser trasladado a un fondo documental encargado de preservar su contenido. Además, debido al vacío histórico y al limitado estado del arte para contextualizar el archivo documental, se hicieron diversas aproximaciones al ensamble y a su historia que permitieron iniciar cuatro estudios más. La importancia de este trabajo radica en el reconocimiento, en el trato y en la significación del valor cultural que supone un archivo musical y el sujeto cultural del cual parte: la banda sinfónica.

Palabras clave: sujeto cultural, archivo musical, partituras, banda sinfónica, investigación formativa

Para citar este artículo: Cárdenas, R., Gutiérrez, A., \& Palencia, R. (2022). El archivo musical documental: subjetividades y aportaciones al sujeto cultural. Praxis \& Saber, 13(32), e12522. https://doi.org/10.19053/22160159.v13.n32.2022.12522 


\title{
The documentary music archive: subjectivities and contributions to the cultural subject
}

\begin{abstract}
This article arises from a research project aimed at recovering the documentary materialmusical scores-used by the Boyacá Wind Symphony Orchestra, whose origin dates back to the end of the 19th century. The group has undergone several transitions in terms of function and organizational affiliation. In 2004 there was an internal restructuring that triggered the beginning of its decline. The study was qualitative-descriptive, with a historical-hermeneutic approach. It was divided into the following phases: (1) diagnosis, (2) classification, characterization, and assessment, (3) organization of the documentary archive, and (4) cataloguing. As a result, a catalog of 328 composers and 757 works was compiled, organized according to archival criteria and ready to be transferred to a documentary fund in charge of preserving its contents. In addition, due to the historical void and the limited state of the art to contextualize the documentary archive, several approaches were made to the orchestra and its history that allowed the initiation of four more research studies. The importance of this work lies in the recognition, treatment, and significance of the cultural value of a musical archive and the cultural subject from which it originates: the symphonic band.
\end{abstract}

Keywords: cultural subject, music archive, musical scores, symphonic band, formative research

\section{$O$ arquivo musical documental: subjetividades e aportes para o sujeito cultural}

\section{Resumo}

Este artigo surge de um projeto de pesquisa que visa a recuperar o material documental partituras musicais - utilizado pela Orquestra Sinfônica de Sopros de Boyacá, cuja origem remonta ao final do século XIX. O grupo passou por várias transições quanto a sua função e afiliação organizacional. Em 2004, aconteceu uma reestruturação interna que desencadeou o início de sua decadência. O estudo foi qualitativo-descritivo, com uma abordagem histórico-hermenêutica. Ele foi dividido nas seguintes fases: (1) diagnóstico, (2) classificação, caracterização e avaliação, (3) organização do arquivo documental e (4) catalogação. Como resultado, foi compilado um catálogo de 328 compositores e 757 obras, organizado de acordo com critérios de arquivamento e pronto para ser transferido para um fundo documental encarregado de preservar seu conteúdo. Além disso, devido ao vazio histórico e ao estado da arte limitado para contextualizar o arquivo documental, foram feitas várias abordagens ao grupo e sua história que permitiram o início de mais quatro estudos de pesquisa. A importância deste trabalho reside no reconhecimento, tratamento e significação do valor cultural de um arquivo musical e do sujeito cultural do qual ele se origina: a banda sinfônica.

Palavras-chave: sujeito cultural, arquivo musical, partituras musicais, banda sinfônica, pesquisa formativa 
El lenguaje musical involucra diversos símbolos y representaciones con los cuales ilustra la música. Esta ilustración surge de la interrelación entre oralidad y escritura, sin ser una relación sine qua non. Sin embargo, las grafías han permitido la pervivencia de determinadas expresiones musicales, las cuales han adquirido historicidad y poder (Cárdenas-Soler et al., 2016), aun cuando en la problemática de la interpretación, planteada por Adorno (2006), se expone que la obra musical no es idéntica a la representación de grafías dispuesta en la partitura (Vieira, 2009). En consecuencia, la suma de la evolución de las grafías y de los signos musicales se traduce principalmente en la partitura, que ha pasado por variados procesos de estructuración: inició como elemento guía para el intérprete hasta convertirse a mediados del siglo XIX en el eje de instrucciones orientativas del compositor, cuyas indicaciones escritas tomaron cada vez más relevancia como parte del discurso musical (Mandolini, 2016). Así, la partitura se convirtió en un elemento para la construcción de subjetividades, desde la forma estilística plasmada por el compositor hasta la interpretación del ejecutante. Este documento musical es visto como una representación externa a partir de la cual se otorgan significados. Con las marcas gráficas la partitura puede permanecer en el tiempo, ser interpretada una y otra vez — desde el discurso musical o desde su sintaxis—, manipulada — arreglada y adaptada — o conservada -memoria musical- (Casas \& Pozo, 2008, p. 51).

La partitura es un documento que permite comunicar aspectos culturales, sociales y expresivos a través del lenguaje musical. Desde su interpretación, es parte activa de procesos de configuración de subjetividades que dan lugar a la experiencia musical, en donde se involucra la individualidad del intérprete, del compositor y del espectador, para fundirse como colectividad en torno al discurso musical, hecho que les permite constituirse como sujetos culturales, ya que la distancia del yo desaparece en la puesta en escena y se suma con los otros, lo cual concreta la sociedad musical como un sujeto cultural, actor que influye y configura su entorno (Dros, 2003). En este sentido, se destaca el valor patrimonial de la partitura en los ámbitos documental y material, pues como bien tangible le otorga sentido, identidad e historicidad al hecho sonoro y justifica su necesaria salvaguarda. Por tratarse de documentos, y como parte inicial del proceso de conservación, es necesario acudir a las técnicas de archivo para conservar las condiciones físicas de los documentos (Fuster-Ruiz, 1999; Reyes, 2016).

La suma de partituras constituye un archivo musical de compositores, arreglistas, intérpretes y agrupaciones, desde donde se recrean las subjetividades que permiten significar el patrimonio documental e histórico del hecho musical como un lenguaje escrito cargado de saberes y experiencias que generan identidad. En este sentido, en el archivo de una agrupación musical se conjugan las huellas que han dinamizado la colectividad cultural: sus partituras, programas de mano, grabaciones y fotografías de las diferentes temporadas y escenarios. Por ello, la memoria de los instrumentos y atriles, la historia oculta tras bambalinas o las múltiples anécdotas que se tejen alrededor de la agrupación son en sí mismas elementos constitutivos de la memoria colectiva de la música y su entorno (Río, 2019).

En consecuencia, el archivo musical es una potente herramienta desde donde es posible analizar el pasado, con miras a hacer reconstrucciones históricas que permitan comprender el proceso de creación de la subjetividad del intérprete, del compositor o del ensamble en torno 
al hecho sonoro. También es un escenario para el análisis, la comprensión y el restablecimiento de la memoria cultural, desde donde se posicionan los actores relacionados con el hacer musical como sujetos culturales responsables de la configuración de procesos identitarios. Es la memoria la que puede decir tanto sobre el pasado en disputa, como sobre el presente que se disputará en tiempos posteriores (Pinilla, 2011). Justamente, desde la memoria colectiva se puede significar y resignificar la memoria cultural, pues la primera permite indagar y detallar los procesos de la segunda (Acuña, 2020). En todo caso, la memoria colectiva se desarrolla en la intersubjetividad, es decir, en las interrelaciones y negociaciones en donde a través del relato los diferentes miembros del grupo determinan qué se olvida y qué se recuerda (Pinilla, 2011).

Los archivos musicales contienen documentos impresos, sonoros, audiovisuales y manuscritos, principalmente de origen análogo, los cuales, dadas sus características propias, representan necesidades de preservación y de tratamiento técnico únicas, sobre las que se debe hacer un importante proceso de indagación, sistematización y actualización (Cabezas, 2005; Quevedo, 2011). En Colombia estos procesos son adelantados principalmente por la Biblioteca Nacional de Colombia y su Centro de Documentación Musical, organismo que expidió la Política para la gestión y salvaguarda del patrimonio bibliográfico y documental (2019), la cual establece una hoja de ruta para preservar los diferentes tipos de documentos considerados patrimonio documental, incluyendo las especificidades para aquellos de contenido musical. Por ello, la adecuada salvaguarda y disposición de los archivos musicales en Colombia es un tema aún naciente y sobre el cual la investigación musical puede aportar de manera significativa.

La historia musical de Colombia puede sustentarse en archivos documentales que son muchos, extensos y variados. Por lo tanto, es necesario que músicos, gestores, historiadores y especialistas en técnicas archivísticas asuman los propósitos de la restauración y de la salvaguarda de este patrimonio documental, para que desde estas prácticas se resignifique y se reconstruya la memoria colectiva de los ensambles que han consolidado la identidad cultural del país (EAFIT, 2009, Reyes, 2016).

\section{La banda sinfónica como sujeto cultural}

Las bandas o sociedades musicales son colectividades integradoras donde se presenta un intercambio intergeneracional, interclasista e histórico, que varía y se transforma para dar tintes identitarios al contexto cultural en el cual se desarrollan (Río, 2019). En este sentido, en Colombia las bandas sinfónicas representan, en muchos casos, el epicentro del desarrollo cultural y artístico de las comunidades (Valencia, 2017). Por lo tanto, la práctica sinfónica poco a poco ha ido ganando espacios para ser reconocida como constructora de identidad social y cultural y ha permeado así varias generaciones.

Es posible afirmar que una banda sinfónica es un sujeto cultural, porque la noción de sujeto cultural implica un proceso de identificación, en cuanto se fundamente en un modo específico de relaciones entre el sujeto y los otros (Dros, 2003), es decir, en la práctica colectiva, como sucede en las bandas sinfónicas. Los sujetos individuales se despiden para dar vida a una identidad colectiva en torno al hecho musical; el yo se confunde con los otros y resulta ser la máscara de todos los otros (Dros, 2003). 
La banda musical es, entonces, un ensamble que solo es posible concebir desde la interrelación de las individualidades en favor de un acto colectivo y artístico que trasciende la sensibilidad del intérprete, sujeto individual, para acudir al tejido de diversas subjetividades y cumplir su papel transgresor de sujeto cultural en un público receptor y cocreador de identidad e historia cultural. A este respecto, Sarmiento (2016), en su estudio sobre el papel de la Banda del Batallón Guardia Presidencial entre 1930 y 1946, concluye que el repertorio interpretado por esta agrupación era principalmente de corte centro europeo, mientras que en las instancias académicas se discutía acerca de la consolidación de una música nacional. Aun así, otras bandas musicales de la ciudad incluían un repertorio mixto, con algunas obras populares y otras específicamente colombianas - pasillos y bambucos-, con lo que se pretendía complacer a la diversidad cultural de la época.

En este sentido, la Orquesta Sinfónica de Vientos de Boyacá (OSVB) fue un proyecto cultural que se desarrolló por más de cien años y generó identidad social y cultural en músicos, gestores y en la comunidad boyacense en general. Se consolidó como el principal sujeto cultural del departamento en el ámbito musical. En este marco contextual, el presente estudio tiene la iniciativa de recuperar el archivo documental, el legado musical y cultural y la historia por contar de cómo, a través de los procesos colectivos culturales de la época en que estuvo activa, la agrupación llegó a convertirse en el más importante actor cultural-musical de la escena boyacense, es decir, la forma en que se consolidó como sujeto cultural.

\section{La Orquesta Sinfónica de Vientos de Boyacá ${ }^{1}$}

Esta agrupación musical, conocida inicialmente como Banda de Músicos del Departamento de Boyacá, inició sus labores artísticas bajo la batuta del maestro Carlos María Torres de la Parra, a finales del siglo XIX, específicamente en 1877, veinte años después de que la Sociedad Filarmónica de Bogotá estableciera la primera orquesta del país e iniciara un movimiento inspirado en las asociaciones filarmónicas de Europa.

Con base en el material documental - decretos y ordenanzas- que reposa en el Archivo Departamental de Boyacá, se logró establecer que los primeros veinticinco años de actividad del ensamble estuvieron marcados por ciclos cortos de auges y decadencias, caracterizados por recesos temporales y reorganizaciones bajo la subvención de instituciones, primero militares y luego civiles, donde los instrumentistas de la banda variaban en muy poco. Es importante aclarar que la historia del movimiento de bandas en Latinoamérica, y de manera particular en Colombia, surgió a propósito de las entidades militares para luego vincularse con temas festivos, religiosos y civiles (Valencia, 2017).

Llegado el siglo XX, en 1918 el entonces gobernador de Boyacá, Domingo Combariza, realizó el nombramiento de 76 músicos para la banda del departamento, a través del Decreto No. 74 (Gobernación de Boyacá, 1918). Estos músicos estuvieron al servicio de la agrupación musical por casi diez años continuos. En 1927 se expidió una norma que los reubicó en el Cuerpo de Guardias de Boyacá. En este periodo de tiempo, son particularmente recordadas

1 Reconstrucción histórica realizada como parte de la investigación Historia de la Escuela Superior de Música de Tunja, en el marco de la Maestría en Historia de la UPTC. 
sus retretas en lugares específicos de la ciudad como el parque Pinzón, el parque de los Mártires y la casa del gobernador, pues hacer este tipo de eventos estaba consignado dentro de los deberes de la agrupación (Decreto 74, Gobernación de Boyacá, 1918). También se menciona la importante labor que cumplía la agrupación de acompañar con música marcial y religiosa los diferentes desfiles militares, civiles y eclesiásticos de la ciudad y del departamento, así como sus presentaciones en sitios emblemáticos de Tunja — capital del departamento y sede de la banda-.

Entre 1939 y 1944, las condiciones contractuales de los músicos cambiaron y el departamento empezó a reconocer su labor artística al asignarles viáticos, prestaciones sociales y derecho a pensión, estipendios que se mantuvieron durante varios años. Más adelante, en 1975, la Junta Directiva de la Corporación de Promoción Cultural presentó ante la Asamblea de Boyacá el proyecto de la Ordenanza No. 23, con la cual, luego de tres debates, se dio origen al Instituto de Cultura y Bellas Artes de Boyacá (ICBA), de manera que la Banda de Músicos es finalmente convertida en dependencia de dicha entidad. Allí culminó este primer periodo de labores de una agrupación con tendencia militar que, de a pocos y por las necesidades contextuales, empezó a migrar a escenarios festivos, religiosos y civiles (Sarmiento, 2016; Valencia, 2017).

Los primeros directores del ICBA fueron los maestros Fernando Soto Aparicio, Carlos Martínez Vargas y Gustavo Mateus Cortés. Este último, en el cargo desde 1977, realizó un proceso de gestión para la importación de instrumentos musicales de percusión sinfónica - timbales, campanas tubulares, xilófonos y vibráfonos- y de cuerdas frotadas - contrabajo-, material con el cual el repertorio que era esencialmente marcial pasó a enriquecerse con música universal. Por lo tanto, y en vista de las nuevas necesidades de repertorio e instrumentales, se amplió la cualificación académica de sus músicos. El público boyacense empezó a generar una afición por asistir a los conciertos semanales, que además ya se desarrollaban en auditorios destinados para tal fin. Stravinsky, Holst, Hindemith, Persichetti, Strauss, Mahler, Shumann, Copland, Bernstein, Mussorgsky, Korsakov, Tchaikovski, Milhaud, Hanson, Dukas, Ravel, Reed, BarnesChance, Dvorak, Zumaqué, Morales Pino, Rozo Contreras, Francisco Cristancho, Adolfo Mejía, Luis Uribe Bueno y Blas Emilio Atehortúa, entre otros, hacían parte del amplio catálogo de compositores que interpretaba la banda para la época, al involucrar músicas universales con obras de compositores colombianos que permitían enriquecer su repertorio y sus alcances.

Desde 1981, la programación de los conciertos apareció con el nuevo nombre: Orquesta Sinfónica de Vientos de Boyacá, debido a que la visión administrativa deseaba restructurar el formato y completar la sección de cuerdas. Por esos años también se vincularon por concurso nuevos instrumentistas y expertos directores titulares e invitados, algunos nacionales y otros internacionales de reconocida trayectoria. Entre ellos estaba el maestro Stanley de Rusha, quien, por su exigente labor frente a la orquesta, solicitó al ICBA la adquisición de nuevas partituras para ser interpretadas en sus conciertos. Durante los años de 1980 y 1990, la OSVB fue reconocida a nivel nacional gracias a la consolidación de Tunja como escenario de la música erudita en el país, en parte, debido a los aportes del Festival Internacional de la Cultura que se desarrollaba desde 1973, el cual aportaba año tras año exigencia y calidad en la labor musical, y de la Escuela Superior de Música de Tunja, institución de formación musical para propios y nacionales.

Hacia finales de 1990, diferentes instituciones reconocieron y exaltaron la labor e importancia 
de la OSVB como sujeto cultural para el departamento, para Colombia y para el mundo. En este sentido, inicialmente en diciembre de 1997, luego de 101 años de fundación del ensamble, la Gobernación de Boyacá condecoró a la orquesta con la Orden de la Libertad en el grado de Gran Oficial (Decreto 2516, Gobernación de Boyacá, 1997). Dos años más tarde, la Asamblea de Boyacá, mediante la Resolución 020 (1999), otorgó la Condecoración Altares de la Patria en el grado de Comendador. Casualmente, en estas dos oportunidades, la orquesta estuvo dirigida por el admirado maestro Jorge Ignacio Zorro Sánchez, quien fue el gestor y fundador de la Escuela Superior de Música de Tunja.

No obstante, el inicio de siglo trajo consigo sorpresas para las entidades culturales, las cuales iniciaron con la promulgación de la Ley 617 (Congreso de la República de Colombia, 2000), por la cual se dictaban normas tendientes a fortalecer la descentralización en el país. Esto propició el inicio de una larga y agonizante crisis cultural nacional con considerables repercusiones en el escenario regional, causante del agobio y de la tensión de músicos, administrativos, gestores y artistas de las diferentes dependencias del que luego se llamó Instituto de Cultura y Turismo de Boyacá. A esta orden nacional, le siguieron el Decreto 0280 (Gobernación de Boyacá, 2004) y la Ordenanza 01 (Asamblea de Boyacá, 2005), con la cual falleció un esfuerzo de 128 años: la agrupación musical y el ICBA murieron por no ser autosostenibles financieramente. Aunque no fue la única banda en el país que cesó sus labores, sí fue la que más luchó por conservar sus derechos, pues, en cabeza de músicos líderes como los maestros Jorge Enrique Pérez - trompetista-, William Antonio Parra — saxofonista- y Miguel Ángel Pinzón clarinetista-, se evidenció la resistencia que en varias oportunidades hizo valer los derechos de un fuero sindical que los cobijaba y la constante motivación de un gremio nacional que, carente de estrategias efectivas, dejó perder la oportunidad de sobrevivir.

La labor de enaltecer la música sinfónica de más de cuarenta reconocidos maestros que pasaron durante más de un siglo por la dirección de la Banda de Músicos del Departamento, Banda Sinfónica de Vientos de Boyacá o, con su última denominación, OSVB, cesó. Su música se calló. La batuta del maestro Fabio Raúl Mesa Ruiz, quien dirigió e hizo arreglos en sus más de 400 conciertos, detuvo su movimiento. La tinta de copistas, transcriptores, instrumentistas, orquestadores y arreglistas, como el Maestro Germán Moreno Sánchez, se secó. Los músicos se distanciaron, algunos por la inevitable muerte. El público de la más importante agrupación boyacense se marchó y sus líderes se fueron a tejer otros destinos. Su archivo musical documental, comprado durante los últimos tres decenios - que conformaron el segundo periodo de vida musical de la banda-, el cual muchas veces fue adquirido por el ICBA, donado por la empresa privada y, en ocasiones, comprado con el dinero que aportaban los músicos a su sindicato, se quedó en anaqueles que hoy resucitan de la mano del proyecto de restauración, conservación y salvaguarda de la memoria documental de la OSVB, representada en sus partituras.

\section{Metodología: la colección de partituras de la OSVB}

Este fue un estudio cualitativo-descriptivo, con enfoque histórico-hermenéutico, desde donde se tomó como objeto de estudio el archivo documental de la OSVB, para recuperar, salvaguardar y disponer las partituras, de manera que se conserven y se valoren por el patrimonio histórico y cultural que representan como bien material del que ha sido el sujeto 
cultural más importante del departamento de Boyacá.

Se abordan en este apartado los aspectos relacionados con el trabajo de campo de la investigación que origina este artículo: El arreglista y la filigrana musical. A propósito de la recuperación documental de partituras de la extinta Banda Sinfónica de Vientos de Boyacá, SGI 2909, financiada por la Vicerrectoría de Investigación y Extensión de la Universidad Pedagógica y Tecnológica de Colombia (UPTC).

La OSVB tenía una connotación de banda sinfónica profesional, por lo cual el desempeño de los músicos participantes era de las más altas calidades artísticas. Se realizaban montajes de concierto completo con solista, solistas invitados, directores invitados y coro invitado. En este sentido, la variedad de su repertorio también era bastante amplia, razón por la cual la agrupación contaba con almacenista y auxiliar de almacén, quienes estaban encargados de la disposición de sillas, atriles, instrumentos y repertorio, representado en las partituras del montaje que había organizado el director de turno. El repertorio, aunque privilegiaba la música centroeuropea, no se suscribía expresamente a ella, sino que también incluía obras latinoamericanas, variedad que le otorgaba la posibilidad de una amplitud en la formación estética de su público, de manera que no se presentara una mirada peyorativa a las músicas populares suramericanas (Aharonián, 2000).

Una vez se disolvió definitivamente la OSVB en 2005, los archivos de partituras pasaron a ser almacenados en cajas y dispuestos en las instalaciones de la Sala José Mosser, lugar que fue una de las principales salas de conciertos de la ciudad de Tunja, luego sede de la Escuela de Música del convenio Colegio de Boyacá-Gobernación de Boyacá, y, por último, por las condiciones de fallas y deterioros estructurales que presenta, depósito y lugar de acopio, donde se llevó a cabo el trabajo de campo a que hace alusión este escrito. Por ello, al ingresar a este espacio, se halló un cuarto con estantes llenos de carpetas, librillos, hojas sueltas y cajas con indeterminada cantidad de partituras. Es decir, se encontró que el archivo documental de partituras estaba almacenado sin el cuidado de tratamiento con técnicas propias de archivo y sin la posibilidad de disponer de estos documentos para un uso académico. Estas partituras, además de otros materiales pertenecientes a lo que fue la Biblioteca Especializada en Música del ICBA, han carecido de atención para ser recuperadas, inventariadas, protegidas y dispuestas para el servicio de la comunidad artística y académica.

Las partituras que constituyen un archivo de tal magnitud -como el que aquí se ha intervenido, de una agrupación musical profesional con cerca de cien años de trayectoriarevelan no solamente la información allí expuesta — discurso musical-, desde los scores y las particellas correspondientes, sino que también muestran los principios estéticos que la banda había asumido. En el caso de las obras musicales, se puede realizar este análisis a partir de los paratextos presentes en las partituras, tales como: anotaciones interpretativas; marcaciones técnicas; correcciones digitales; nombre del compositor, arreglista o adaptador; y fecha en la que fue escrita, arreglada o adaptada la obra.

Para la interpretación musical, conocer el contexto histórico de "creación" de la obra y aspectos biográficos del "autor" es un insumo base para las decisiones musicales que deba tomar el director de una agrupación musical y el instrumentista mismo. En este sentido, la 
interpretación musical requiere de un cuidadoso análisis estructural de las obras, de manera que el discurso musical sea coherente en términos estilísticos y pueda ser comprensible de acuerdo con el contexto en el cual se desarrolla. De esta forma, luego de centrar el escrito en el recuento histórico y contextual de la colección documental, se hará referencia al desarrollo del trabajo de recuperación y disposición documental, según la secuencia: (1) diagnóstico, (2) clasificación, caracterización y valoración, (3) organización de la colección documental y (4) catalogación. También se describe el proceso de variación de la propuesta inicial, que se ha enriquecido de diversas perspectivas al tener como principal aliada la investigación formativa.

La organización de los documentos obedece a una lógica, definida o por definir. De igual forma, un archivo no es un depósito de documentos, porque el archivo ha tenido un tratamiento específico para su organización, un orden; el depósito de documentos, no necesariamente (Jaén, 1998). En este sentido, la etapa diagnóstica cobra relevancia. Por ello, además de ser la primera fase de la investigación, fue la actividad fundamental que permitió estructurar el trabajo a seguir. Inicialmente, fue necesaria una inspección para ubicar el material documental e identificar sus dimensiones y estado. Se encontró un espacio cerrado, con cuatro estanterías donde se ubicaban carpetas de partituras y algunas cajas en el suelo que almacenaban hojas sueltas, obras completas y documentos. Por ello, se realizó una primera limpieza con las debidas precauciones y cuidado para el manejo documental, pues, al estar almacenados los documentos en un lugar cerrado, podían contener ácaros que impedirían un fácil trabajo individual. Se estableció como resultado del diagnóstico un inventario general con un total de 492 legajos dispuestos en 85 cajas de archivo, las cuales fueron reubicadas en un lugar aireado de la misma sala José Mosser. La documentación podía catalogarse, desde la archivística, como perteneciente a un fondo cerrado - todos los documentos encontrados estaban relacionados con la OSVB: partituras, oficios y cuadernillos-, por lo cual se determinó la siguiente estructura para el archivo:

- Fondo documental: Gobernación de Boyacá.

- Sección: ICBA-Secretaría de Cultura.

- Subsección: Escuela Superior de Música.

- Serie documental: partituras OSVB.

En esta fase diagnóstica no se verificó el contenido de cada carpeta, ni la organización o estado de la obra, pues solo se pretendía conocer la dimensión y estado real del archivo documental.

La segunda fase consistió en la clasificación, caracterización y valoración, tres elementos básicos constitutivos de la organización de archivos. Se tomó como punto de partida el inventario físico que el maestro Fabio Raúl Mesa Ruíz había hecho para la entrega del material en el 2005. Este documento permitió la identificación de obras y de intérpretes que el equipo de investigación encontró en el conjunto documental, información que sugirió las primeras decisiones en cuanto a disposición física de la colección documental, a unidades de conservación, a foliación, a codificación y a identificación y estructura del catálogo. Se identificó entonces que el fondo documental estaba compuesto por oficios institucionales, librillos con el score de obras universales, carpetas con obras - algunas no estaban en buenas 
condiciones; eran fotocopias, con hojas amarillentas, pegadas con cintas o ganchos- y carpetas con particellas de un instrumento. Los tamaños de los folios también eran diversos: se hallaron algunos en oficio, otros en carta, media carta o cuarto de carta y otros con tamaño extragrande. Igualmente se determinó que unas partituras correspondían a casas editoras y eran originales; otras eran copia. Incluso se encontraron algunos manuscritos. Había varias obras con full score, otras con reducción o con guía - alguna parte instrumental se convertía en guía, como la flauta- y otras sin score.

La tercera fase fue la organización de la colección documental. Inició con la determinación de revisar individualmente las obras, en un proceso que el equipo de investigación denominó "curaduría musical", para disponer sus partes según el orden que proponía el score -cuando la obra lo contenía - o según el orden universal del formato. Entonces, se acordó incluir en un primer apartado las partes principales - una copia de cada cuerda- y en un segundo apartado las partes restantes, porque, según la disposición del archivo, los duplicados se eliminan. Sin embargo, al tratarse de obras que se pretende que sigan circulando para ser interpretadas, se consideró pertinente dejar los duplicados, además, por su valor de bien patrimonial. Una vez organizada la obra, en una matriz diseñada específicamente para el estudio, se procedió a describir: por un lado, número de folios de la parte principal, número de folios de duplicados, estado del score y número total de folios; y por otro, estado y anotaciones para las partes - se detallaba si estaban completas, qué partes faltaban, de cuáles había duplicado y el estado de conservación de las partes-. Se asignó el código del compositor y de la obra a la carpeta que contenía los folios y se describió el número de caja donde quedaba ubicada dicha obra. De esta fase resultó un total de 757 obras de 328 compositores y 66 anónimos. Una vez terminada esta revisión individual de obras, se encontró un número significativo de folios perdidos, cuyo trabajo de reubicación resultó dispendioso, por la magnitud de carpetas y la disposición en las cajas. Además, se requería cambiar la descripción en la matriz.

En la última etapa, la catalogación, se decidió organizar alfabéticamente el material compilado por apellido de compositor, lo cual requirió de una reasignación de códigos y cajas, que consideramos tendrá mayor facilidad en su manejo posterior. De igual manera, se proyectó enriquecer el catálogo resultante con una descripción biográfica de los compositores y digitalizar las obras, acciones que fueron consolidadas gracias a los procesos de investigación formativa en los proyectos que se describen en la siguiente sección.

Este proyecto enriquece, colorea, llena de matices y resignifica la labor y documentación del único ensamble sinfónico profesional de Boyacá hasta la fecha (Palencia, 2016). Entre tanto, lo que inicialmente pretendía arrancar del olvido y restaurar el legado musical documental de este ensamble ha ido variando al enriquecerse de múltiples experiencias y perspectivas que han permitido proponer espacios para la memoria musical, colectiva, histórica, pero principalmente para la memoria cultural de generaciones de ilustres músicos y gestores del departamento, que con su labor consolidaron la OSVB como un sujeto cultural activo, en el establecimiento de la identidad tunjana y boyacense, a partir de los espacios musicales y artísticos que, para la época de la banda, hicieron de Boyacá un importante escenario de interés cultural y artístico en el marco nacional e internacional. 


\section{Variación y evolución desde la investigación formativa}

La variación es un hecho biológico nato que, a través de diferentes procesos de adaptación y transformación, permite la diversificación de un algo, al enriquecerlo, adaptarlo a nuevos contextos y permitirle evolucionar de cara a las necesidades contextuales. Se puede decir que sin variación no hay diversidad y sin diversidad no hay evolución (Hernández \& Noguera, 2009). La variación implica intervención, contraste, cambios y transformaciones que permiten desde nuevas ópticas desarrollar formas alternas de ver y de entender un todo. Por lo tanto, es una necesaria y poderosa herramienta en el área investigativa y educativa, porque, desde estas variaciones, alternancias, cambios y evoluciones, se da lugar a la innovación como elemento necesario en la educación del siglo XXI (Carbonell, 2015).

En este sentido, la investigación formativa es una fuente de variación y de cambio educativo, en tanto permite indagar por propuestas frente a los cuestionamientos o preguntas sugerentes, siempre desde el aprendizaje significativo, experiencial y autónomo, para enriquecer y transformar las realidades contextuales de los investigadores noveles (Espinoza, 2020; Villalba \& Gonzáles, 2017). Este proceso formativo busca generar cambios en el contexto sociocultural no solo de los investigadores, sino de las comunidades involucradas en el proceso investigativo. Para este caso particular, además, se suma el hecho de convertir los procesos de formación musical en escenarios de exploración investigativa que permiten la comprensión de los hechos culturales desde las propias identidades regionales. Se toman las historias, las memorias y las transformaciones del entorno como eje que posibilita la comprensión de la situación actual del ejercicio musical y artístico en Colombia, para promover acciones tendientes a su resignificación social (Arenas, 2015; Samper, 2016).

La exploración, las alternancias y la variación investigativa son los hilos que han permitido tejer el entramado de recuperación, preservación y salvaguarda del archivo de partituras de la OSVB. De igual forma, las experiencias de investigación formativa son la aguja que ha bordado nuevas perspectivas para enriquecer, trasformar y evolucionar los horizontes del proyecto. Las investigaciones que se presentan a continuación inicialmente fueron proyectadas a futuro. Sin embargo, gracias al trabajo mancomunado con semilleros de investigación, a la fecha están en sus fases finales de desarrollo.

En consecuencia, como primer hilo, y teniendo en cuenta las posibilidades de los medios digitales como herramientas que permiten proteger y preservar la documentación musical del deterioro físico, y además favorecer las formas de acceso y consulta a este tipo de material documental ${ }^{2}$, surge el proyecto Digitalización de obras musicales: a propósito del catálogo de partituras de la $O S B V$, El cual tiene como eje la transición del estado físico de las partituras a uno digital como un hecho necesario que posibilita el desarrollo de un objeto virtual, para dinamizar el uso y circulación del repertorio del extinto ensamble en la escena musical colombiana, toda vez que es deber de los procesos de restauración y patrimonialización documental garantizar la evolución del archivo documental al medio digital (Cabezas, 2005; Quevedo, 2011).

2 La Biblioteca Nacional de Colombia ha establecido recientemente como documento orientador para procesos de digitalización documental la Guía de digitalización y preservación digital (2020). 
Por otra parte, con el ánimo de aportar al enriquecimiento del catálogo y de potenciar la comprensión integral de la labor y del desarrollo musical del ensamble, el proyecto $E l$ compositor y su obra, a propósito del inventario de partituras que fueron interpretadas por la OSVB se propuso realizar la descripción biográfica de los 328 compositores de las obras que reposan en el archivo documental, a partir de fichas de caracterización construidas bajo criterios que propone la musicología, sin extenderse en su contenido. Estas fichas se anexaron al catálogo principal, dispuesto en un archivo virtual que a la fecha se suma al archivo físico de partituras digitalizadas. Este objeto virtual está en custodia de los grupos de investigación, a la espera de resolver temas de derechos de autor y del desarrollo de los procesos técnicos que permitan su circulación.

Asimismo, y con la intención de continuar contribuyendo con diversas perspectivas analíticas e históricas al catálogo general, el proyecto Historia de vida de los arreglistas boyacenses y su aporte a la OSVB busca compilar la historia de vida de los arreglistas boyacenses más representativos, cuyo trabajo se vio reflejado de manera significativa en el archivo documental. Se pretende, por un lado, determinar el aporte que hicieron a la agrupación, su historia y su interacción con la banda y, por otro, a través de su experiencia, evidenciar y resignificar la labor del arreglista en una agrupación profesional de vientos, ya que el arreglista dota de múltiples identidades, sentidos y significados a las agrupaciones musicales, a partir de las diversas formas de interacción musical y social de estas con el entorno cultural (Valencia, 2017). Para hacer posible la circulación de la memoria colectiva de los arreglistas en torno a la banda boyacense, se realiza un producto audiovisual que igualmente favorece la reconstrucción histórica e identitaria de toda una generación de músicos y gestores. Este producto se desarrolla como estrategia de investigación-creación y se ajusta a los mecanismos de acceso, difusión y apropiación social que determina la política para la gestión del patrimonio bibliográfico y documental.

Finalmente, como último hilo de este tejido histórico y cultural, el proyecto La OSVB 20002005. Reconstrucción histórica y perspectiva de los intérpretes, financiado por la UPTC a partir de una beca de maestría, pretende, en primer lugar, desde la investigación documental y los procesos individuales de memoria, consolidar la perspectiva respecto de lo que significó la banda y, así mismo, establecer el legado social, cultural y musical del ensamble en sus últimos años y lo que acarreó su cierre definitivo para la escena musical y cultural boyacense. En suma, se trata de hacer un ejercicio de memoria colectiva para resignificar, revalorar y rescatar del olvido el aporte histórico cultural del ensamble sinfónico más relevante del departamento de Boyacá hasta el momento.

\section{Coda}

En definitiva, los proyectos descritos dan muestra del interés general de las autoras por rescatar la historia y el legado de la OSVB, a partir de la interacción con los sujetos como actores independientes que a través de su experiencia permiten reconstruir parte de la memoria cultural del departamento de Boyacá. Teniendo en cuenta la voz de directores, gestores, intérpretes, arreglistas y seguidores del ensamble, se ha buscado reconstruir la memoria colectiva de la banda. Es necesario acudir a procesos de memoria colectiva para la consolidación y restauración 
de una memoria cultural (Acuña, 2020), la cual permite el afianzamiento de la memoria integral del ensamble y la caracterización de procesos de identidad que se desarrollaron culturalmente en el departamento y que se desea que sean trasladados a las memorias de las nuevas generaciones.

Por otra parte, es fundamental evidenciar la importancia de la investigación formativa como eje articulador de experiencias y propuestas transformadoras que posibilitan redes de enseñanza-aprendizaje bidireccionales entre el saber del maestro y el saber de los estudiantes. Se trata de interrelaciones efectivas entre el sujeto cultural y el sujeto social como actor investigativo, lo cual implica resignificar y ampliar las perspectivas en procesos de innovación, transformación y creación de la investigación (Espinoza 2020; Villalba \& Gonzáles, 2017).

Este proyecto es una apuesta que varía, altera y, desde la investigación, denuncia la normalidad y el abandono que han llevado al olvido del legado y de la memoria del emblemático ensamble boyacense. También se erige como una propuesta para tomar acciones, desde la investigación musical y formativa, con el fin de garantizar la continuidad de todo tipo de proyectos que innoven, transformen, varíen, intervengan, y, sobre todo, se interesen por cambiar el trato que históricamente se le ha dado a la actividad cultural, al resignificarla, reposicionarla y recrearla desde el ejercicio participativo de la investigación.

\section{Conclusiones}

En el marco de la memoria y del olvido, es necesario comprender los ensambles musicales como sujetos de cultura y creadores de subjetividades que trascienden a través de la música hacia conglomerados de identidad que conjugan la participación de tres actores fundamentales de la experiencia musical: compositor - creador-, intérprete y espectador. Así, la investigación y sus procesos formativos son un medio eficaz que permite articular los esfuerzos y las perspectivas de cultores, gestores, músicos y académicos, en favor de restaurar, rescatar y salvaguardar la historia que guardan las diferentes colectividades que representan los sujetos de cultura, sus archivos, sus experiencias y sus historias de vida, para participar activamente en la construcción de la memoria cultural de Colombia.

Colombia es dueña de una rica tradición de bandas. Sin embargo, no posee una memoria documentada de tal riqueza. Por ello, es menester de los investigadores, músicos, gestores e historiadores desarrollar acciones encaminadas a rescatar, restaurar y salvaguardar la memoria y legado de estas agrupaciones, que reposa no solo en las fuentes vivas, sino también en los archivos documentales que pueden dar testimonio de la memoria cultural de los ensambles, así como su proceso y aportación como sujeto cultural al entorno artístico nacional y regional, para que desde estas prácticas se resignifique la labor del arte como forjador de identidades.

Se requiere mayor atención de los altos dignatarios nacionales y departamentales en Colombia en relación con los procesos culturales que se desarrollan y se han desarrollado en el país. De ser posible, sería importante contar con una representatividad de los artistas en estos planos del gobierno, para que desde sus saberes logren dar cimiento, estructura sólida y fortalecimientos a las políticas públicas del arte, especialmente de la música, de sus músicos y de las tradiciones que han venido construyendo y heredando. Son los artistas quienes con 
firme convicción esperan que el futuro no repita las tristes decisiones que en su nombre han tomado aquellos que no gobiernan desde la estimación a la patria, sino desde la subjetividad, el desconocimiento, la improvisación, la subvaloración y con escasa sensibilidad hacia lo cultural y su valor social. Lo fundamental deja de ser importante, pero la imagen del artista, la memoria histórica construida por años y la sensibilidad artística seguirán corriendo por las venas del pueblo. Por lo tanto, hay que encargarse de que esto no sea olvido, sino que sea historia.

\section{Referencias}

Acuña, O. (2020). Memorias sociales y culturales. Un debate en construcción [Editorial]. Historia y Memoria, (20), 11-20. https:/doi.org/10.19053/20275137.n20.2020.10311

Adorno, T. (2006). Escritos Musicales I-III. Akal.

Aharonián, C. (2000). Músicas populares y educación en América Latina. En Actas Electrónicas del III Congreso Latinoamericano de la Asociación Internacional para el Estudio de la Música Popular Rama Latinoamericana (pp. 6-23). IASPM-AL. http://ipamardelplata.edu.ar/wp-content/ uploads/2014/04/3-Bibliograf\%C3\%ADa-Aharonian-1.pdf

Arenas, E. (2015). Una perspectiva y ocho invitaciones al diálogo. Ricercare, (4), 27-37. https://doi. org/10.17230/ricercare.2015.4.3

Asamblea de Boyacá. (1975). Ordenanza No. 23.

Asamblea de Boyacá. (1999, 1 de diciembre). Resolución 020. Por la cual se otorga la condecoración Altares de la Patria en el grado de Comendadora a la Orquesta Sinfónica de Vientos de Boyacá.

Asamblea de Boyacá. (2005, 25 de marzo). Ordenanza 001. Por el cual se conceden facultades al gobernador del departamento de Boyacá para transformar el Instituto de Cultura y Turismo de Boyacá en Secretaría de Cultura de Boyacá y se dictan otras disposiciones

Biblioteca Nacional de Colombia. (2019). Política para la gestión del patrimonio bibliográfico y documental. Ministerio de Cultura. https://bibliotecanacional.gov.co/es-co/formacion/caja-de-herramientas/ Documents/Poli\%CC\%81tica_Gesti\%C3\%B3n_Patrimonio_BD.pdf

Biblioteca Nacional de Colombia. (2020, 26 de febrero). Guía de digitalización y preservación digital de la Biblioteca Nacional de Colombia. Ministerio de Cultura.

Cabezas, E. (2005). La organización de archivos musicales: marco conceptual. Información, Cultura y Sociedad, (13), 81-99. https://doi.org/10.34096/ics.i13.899

Carbonell, J. (2015). Las pedagogías del siglo XXI. Octaedro.

Cárdenas-Soler, R., Martínez, J., \& Cremades-Andreu, R. (2017). Competencias de lectura y escritura en música. Una propuesta para su asimilación en el currículo escolar. Cuadernos de Lingüística Hispánica, (29), 181-201. https://www.doi.org/10.19053/0121053x.n29.2017.5859

Casas, A., \& Pozo, J. (2008). ¿Cómo se utilizan las partituras en la enseñanza y el aprendizaje de la música? Cultura y Educación, 20(1), 49-62.

Congreso de la República de Colombia. (2000, 6 de octubre). Ley 617. Por la cual se reforma parcialmente la Ley 136 de 1994, el Decreto Extraordinario 1222 de 1986, se adiciona la Ley Orgánica de Presupuesto, el Decreto 1421 de 1993, se dictan otras normas tendientes a fortalecer la descentralización, y se 
dictan normas para la racionalización del gasto público nacional.

Dros, E. (2003). Sujeto cultural: sociocrítica y psicoanálisis. Fondo Editorial Universidad EAFIT.

EAFIT. (2009). En busca de las partituras perdidas. http://www.eafit.edu.co/EafitCn/Noticias/ En+busca+de+las+partituras+perdidas.htm

Espinoza, E. (2020). La investigación formativa. Una reflexión teórica. Conrado, 16(74), 45-53. https:// conrado.ucf.edu.cu/index.php/conrado/article/view/1332/1323

Fuster-Ruiz, F. (1999). Archivística, archivo, documento de archivo. Necesidad de clarificar los conceptos. Anales de documentación, (2), 103-120. https://revistas.um.es/analesdoc/article/view/2631/2611

Gobernación de Boyacá. (1918, 31 de mayo). Decreto reglamentario 74. En el que se establecen las obligaciones de la Banda de Músicos del Departamento de Boyacá.

Gobernación de Boyacá. (1997, 10 de diciembre). Decreto 2516. Conferir condecoración de Orden de la Libertad en el grado de Gran Oficial a la Banda Sinfónica de Vientos de Boyacá.

Gobernación de Boyacá. (2004, 7 de abril). Decreto 0280. Por medio del cual se y adiciona y modifica la estructura y estatuto básico del Instituto de Cultura y Bellas Artes de Boyacá ICBA.

Hernández, V., \& Noguera, R. (2009). Variación: el universo infinito de las entidades biológicas. Revista Digital Universitaria, 10(6), 1-12. https://www.revista.unam.mx/vol.10/num6/art35/int35-4.htm\#a

Jaén, L. (1998). El diagnóstico archivístico. Una propuesta metodológica. Revista del Archivo Nacional, (62), 11-47. http://www.dgan.go.cr/ran/index.php/RAN/article/view/265

Mandolini, R. (2016). Semiología musical y musicología: aportes de la filosofía de la complejidad. Panambí: Revista de Investigaciones Artísticas, (2), 27-46.

Palencia, R. (2016). Historia de la Escuela Superior de Música de Tunja. Jotamar.

Pinilla, A. (2011). La memoria y la construcción de lo subjetivo. Revista Folios, (34), 15-24.

Quevedo, J. (2011). El documento musical en Colombia: la develación de una memoria oculta que la cartografía de prácticas musicales en Colombia ha convertido en una estrategia de investigación y conocimiento. Signo y Pensamiento, 30(59), 146-154. https://doi.org/10.11144/Javeriana.syp3159.dmcd

Reyes, A. (2016). Los acervos de documentos musicales. ¿Libros raros, libros especiales? Investigación Bibliotecológica, 30(70), 129-163. http://dx.doi.org/10.1016/j.ibbai.2016.10.007

Río del, Berta. (2019). Crear para existir: otras historias de vida en los archivos de la cultura popular. Revista Digital de Musicología, (10), 1-12. https://avamus.org/wp-content/uploads/2020/04/QDVBerta-del-Rio.pdf

Samper, A. (2016). La educación musical como derecho humano: hacia una pedagogía estética, ética y diversa [Editorial]. Cuadernos de Música, Artes Visuales y Artes Escénicas, 11(1), 9-13.

Sarmiento, M. (2016). Bandas militares y repertorio en Colombia: el caso de la banda del Batallón Guardia Presidencial, 1930-1946. Ensayos. Historia y Teoría del Arte, 20(31), 65-92.

Valencia, V. (2017). Música para banda en Colombia. Territorios, sentidos de la creación y rasgos del arreglista-compositor. Pensamiento, Palabra y Obra, 18(18), 101-110. https://doi.org/10.17227/ppo. num18-6287 
Vieira, M. (2009). La partitura como «espíritu sedimentado»: en torno a la teoría de la interpretación musical de Adorno. Azafea, Revista de Filosofía, 11(1), 143-161.

Villalba, J., \& González, A. (2017). La importancia de los semilleros de investigación. Revista Prolegómenos, 20(39), 9-10. 